\title{
Behavior Rating Inventory of Executive
} Function

National Cancer Institute

\section{Source}

National Cancer Institute. Behavior Rating Inventory of Executive Function. NCI

Thesaurus. Code C121459.

A standardized rating scale designed to assess the executive function behaviors in the school and home environments for children and adolescents as observed by a parent or teacher. 